\title{
MITTE-EESTLASTEST NOORTE KOHANEMINE EESTIKEELSES TÖÖKESKKONNAS
}

\section{Elvira Küün}

\begin{abstract}
Ülevaade. Artiklis uuritakse noorte mitte-eestlaste kohanemisvõimalusi eestikeelses töökeskkonnas olenevalt eesti keele oskuse tasemest. Vaatluse all on nii töö tulemused, suhted kaastöötajatega kui ka olmesuhted. Eesmärk on välja selgitada, kuidas muulastest noored saavad hakkama Eestis pärast venekeelse kooli lõpetamist, kuidas mõjutab keeleprobleem ja rahvus nende väljavaateid Eesti tööturul ning kuidas kohanetakse eestikeelses töökeskkonnas. Võrreldud on Tallinnast ja Ida-Virumaalt pärit noorte sotsiaalset adaptatsiooni. Uurimuse läbiviimisel on meetodina kasutatud kirjalikku küsitlust ja intervjuud.
\end{abstract}

Võtmesõnad: integratsioon, keelepoliitika, kakskeelsus, teise keele omandamine, eesti keel teise keelena

\section{Sissejuhatus}

Harilikult mõeldakse kultuuri all ennekõike kunsti, kirjandust, muusikat, rahvaloomingut, haridust ja kasvatust. Peale selle aga on kultuuri osaks samuti ajaloolise pärandina saadud usuliste, poliitiliste ja esteetiliste väärtushinnangute kogum, mis omandatakse sotsialiseerumisprotsessis ja mis on vähemalt osaliselt ühine inimestele, kes elavad või on elanud ühesuguses sotsiaalses ümbruses (Pajupuu 2000: 11). Kultuur annab rühmale identiteedi ja teeb selle ainulaadseks. Tove Skutnabb-Kangase (2000: 227) hinnangul hõlmab kultuur materiaalseid ja ideoloogilisi meetodeid, mille abil inimrühm korraldab, muudab mõistetavaks ja taastoodab oma elu rühmana.

Sageli kasutatakse terminit multikultuur selleks, et kirjeldada etniliste rühmade, kultuuride, religioonide ja keelte paljusust ühiskonnas, kuid peale selle väljendab see ka eri päritolu isikute ning rühmade kooseksisteerimist. Riik, mis 
püstitab endale eesmärgi immigrante ühiskonda integreerida, peab toime tulema suure hulga rühmadega, kes erinevad üksteisest oma tausta, suuruse, demograafilise struktuuri ja migratsiooniajaloo poolest (Pajupuu 2000: 47). Integratsioon pole ainult Eesti probleem, see on aktuaalne nii Euroopas kui ka Ameerikas.

Ameerika Ühendriigid, Kanada ja Austraalia on oma ülesehituselt olnud multikultuursed algusest peale. Need on põhiliselt sisserännanute ühiskonnad, kus immigrandid on saanud enamuse oma kodumaal. Nende multikultuurne poliitika on erinev riikidest, mis on tekkinud monokultuursena, nagu Skandinaavia maad. Kolmanda liigi moodustavad Suurbritannia, Saksamaa ja Prantsusmaa, kus mõjutajaks on olnud koloniaalne ajalugu (Hallik jt 1997).

Praktiliselt kõik Euroopa riigid on multikultuursed. Kuna peale etniliste ja keeleliste eripärasuste loetakse multikultuurseks ka erinevaid eluviise, käitumisnorme, mõtlemisviise ja väärtushinnanguid, siis muutub igal järgneval põlvkonnal üha raskemaks ennast identifitseerida (Kallas 2001: 87). Muukeelse inimese identiteedi määravad ära järgmised suhetevahelised seosed: suhtumine iseendasse ja oma rahvusrühma liikmetesse, samuti teiste rahvusrühmade liikmetesse ning kohalikesse elanikesse või enamusrühma liikmetesse (Liebkind 1995: 264). Multikultuurse ühiskonna rajamine on pikaajaline protsess, mida mõista on küllaltki keeruline.

Eestis kerkis sotsiaalse integratsiooni probleem üles suhteliselt hilja, alles 1990. aastate alguses. Seetõttu on Eestil võrreldes teiste riikidega multikultuurse ühiskonna moodustamisel teatavaid iseärasusi (Kallas 2002: 113). Pärast taasiseseisvumist seisis Eesti riik fakti ees, et siin toimib kaks suhteliselt eraldiseisvat keelekooslust - eesti- ja venekeelne. See piir kahe maailma vahel on küllaltki tuntav. Selline kahe keelekogukonna olemasolu on ühiskonna arengus takistuseks (Saks jt 2000). Seega on selge tegutsemisstrateegia loomine muulaste probleemi puhul väga oluline.

Riigi huvides on, et tema kodanikkond oleks piisavalt homogeenne, et selle liikmed võiksid tõhusalt koos toimida. Väga tähtis on ühine keeleruum, kus kõigil ühiskonna liikmetel oleks võrdne võimalus hankida mitmekesist ja neile vajalikku informatsiooni. Muulastel on selle juures sageli probleemiks eesti keele oskus ja sellega kaasnev kodakondsuse puudumine ning seetõttu ei ole nad konkurentsivõimelised tööturul (Saks jt 200o).

Keelekeskkonnas toimuvad nähtused on sõltuvuses võimusuhetest. Seda mõjutavad tegurid kuuluvad keelepoliitika ja keelekorralduse valdkonda. Keelepoliitika põhitegevus on keelekeskkonna regulatsioon, lähtudes järgmistest eesmärkidest: keele säilitamine, konkurentsivõime suurendamine, teiste keelte väljatõrjumine jne (Rannut jt 2003). Oskusliku ja aktiivse keelepoliitika tagamise eest vastutab riik.

Keelepoliitika üheks regulatsiooni objektiks on haridus. Viimane peaks mitmekultuurses perspektiivis aitama kiiresti muutuva ühiskonna liikmetel kujundada oma identiteeti ja seostada seda teistega, ennetada ja lahendada kultuurierinevustest tingitud konflikte (Trasberg 2002: 14). Mitmekeelse ja -kultuurse ühiskonna hariduskorraldus on keeruline probleem. Vähe on neid riike, kus see küsimus on lahendatud kõiki osapooli rahuldavalt. Integratsiooni seisukohalt on tähtis, et riigis toimib ühtne haridussüsteem, mis tagab kõigile üheväärse kvaliteediga hariduse, sõltumata õppijate etnilisest või keelelisest taustast (Hallik jt 1997). 
Kool täidab mitmeid eri funktsioone. Kõrvuti akadeemilise ja selekteeriva funktsiooniga on kool mistahes ühiskonnas sotsialiseerumise vahend: koolis luuakse eeldused, et sobituda ühiskonda. Sotsialiseerumine kui sotsiaalse kogemuse omandamine ja ühiskonda sobitumine on universaalne protsess, mis kulgeb kogu elu (Rannut 1999: 62). Koolis läbitakse sellest oluline osa, mis kujundab antud elutsüklile omases vormis hoiakud ja maailmapildi, millest lähtuvalt toimub edasine areng. Kohandumine sõltub sellest, kuivõrd on võimalik suhelda teiste ühiskonna liikmetega. Paljud noored asuvad pärast kooli lõpetamist kohe tööle, seega on väga oluline see, kuidas nad kohanevad töökeskkonnas.

Keelesotsioloogilisi uurimusi ei ole Eestis palju tehtud, käesolev artikkel toetub autori bakaleureusetöö (Küün 2004) materjalile.

\section{Uurimuse taust}

Uurimustöö eesmärk oli välja selgitada, kuidas muukeelsed noored kohanevad eestikeelses töökeskkonnas, kas eesti keele oskuse tase mõjutab töökoha valikut ja töötulemusi, kas on diskrimineerimiskogemusi seoses keeleoskusega, kas kindlustunne tuleviku suhtes ja tulevikuplaanid on seotud keeleoskusega, milliseid telesaateid noored vaatavad ja kui palju suheldakse eestlastega. Samuti sooviti teada, kas edukus edaspidises elus on seotud riigikeele oskuse tasemega. Uurimismeetodina kasutati kirjalikku küsitlust ja intervjuud. Küsitleti 2001. ja 2002. aastal keskhariduse omandanud noori.

Noored mitte-eestlased vastasid küsitlusele kirjalikult. Küsimustik kujutas endast valikvastustega testi, vastamiseks oli aega 20 minutit. Küsitleti kokku 40 noort Tallinnast ja Ida-Virumaalt (kummastki piirkonnast 20). Noorte vanus jäi vahemikku 18-23 aastat, neide ja noormehi oli võrdselt (mõlemaid 20).

15 noort (Ida-Virumaa 20-st küsitletust) oli pärit Aserist. Aseri noori tundis küsitluse läbiviija isiklikult, kuna oli samuti lõpetanud Aseri Keskkooli, kuid selle eestikeelse, mitte venekeelse osakonna. 15-st 7 olid kooli lõpetanud 2001. aastal, kaheksa 2002. aastal ning nad kõik töötasid Aseris. Ülejäänud 5 noort olid lõpetanud Kiviõli vene õppekeelega keskkooli ja kontaktandmed saadigi koolist. Need noored elasid Püssis, aga nad olid opppinud Kiviõlis. Küsitleja käis kohapeal nendega vestlemas ja samal ajal vastati ka testi küsimustele. Tallinna 20 küsitletust 14 olid küsitleja tuttavad, 6 kontaktandmed saadi koolidest.

Intervjueeriti 2 noort (üks pärit Tallinnast, teine Ida-Virumaalt), et uurida põhjalikumalt noorte enda arvamust eestikeelses töökeskkonnas toimetuleku kohta ning teha kindlaks nende eesti keele oskuse tegelik (suuline) tase. Üks mitteeestlasest intervjueeritav oli antud töö autori kursusekaaslane, teine aga ammune tuttav Aserist.

Küsitletutest 70\% olid ükskeelsest, 30\% kakskeelsest perekonnast. Juhul kui üks vanematest oli eestlane, oli harilikult tegemist kakskeelse perekonnaga. Kui üks vanematest oli venelane, teine mingist muust rahvusest mitte-eestlane, siis oli kodune keel vene keel. Koduse keele määras suures osas ära ema rahvus ja tema emakeel. Kõik küsitlusele vastanud olid lõpetanud vene kooli.

Küsitletud noortest 40\% olid lõpetanud keskkooli, 25\% kutsekooli ning 35\% õppisid kõrgkoolis. Viimased olid põhiliselt Tallinna noored, Ida-Virumaal oli rohkem neid, kes olid lõpetanud kutsekooli. 


\section{Mitte-eestlastest noorte eesti keele oskus}

Kui võtta vaatluse alla Eesti eri piirkonnad, siis on näha, et riigikeele oskus nagu ka rahvuslik koosseis on küllaltki erinev. Rahvaloenduse (2000) andmetel on kõige rohkem mitte-eestlasi Tallinnas ja Ida-Virumaal. Tallinnas on neid 46,2\%, Ida-Virumaal 80,02\%, Eestis kokku 22,1\%. Kui võrrelda eesti keele oskust, siis Ida-Virumaal Aseris on see 50,93\%, Püssis 27,44\%, Tallinnas 42,93\%.

Eesti keelt võõrkeelena on õpetatud vastavalt riiklikele õppekavadele alates 1. klassist. Seadusandluse järgi tuleb alates 2007. aastast vene õppekeelega gümnaasiumides tagada õppekava 60\% ulatuses eesti keeles. Riigikeele õpetamisel on aga probleemiks õpetajate vähesus ja nende puudulik pädevus. Paljud õpetajad ei tunne piisavalt Eesti ainestikku ja traditsioone. Nende eesti keele oskuse tasemest ei piisa tihti olmeliseks ja ainealaseks suhtlemiseks. Keelekoolituski ei ole sageli tulemuslik (Saks jt 2000). Ühiskonnaliikmete konkurentsivõime ühiskonnas tuleb tagada riiklikul tasemel, kavandades keeleõppeks kõige sobivamaid haridusprogramme.

Venekeelsed noored leiavad, et eesti keele oskuse täiustamiseks on väga oluline kontakt eestlastega, st eestikeelne keelekeskkond. Vähene riigikeeleoskus põhjustab selle, et mitte-eestlaste konkurentsivõime on tööturul väiksem kui eestlastel. Küsitletud noortest 30\% pidas oma eesti keele oskust väga heaks, 40\% heaks ja 30\% rahuldavaks. Mitterahuldavaks ei hinnanud oma keeleoskust keegi. Eesti keele riigieksami tulemused olid suhteliselt head (61-93 palli). Kõrgem oli see üldiselt neil, kes olid lõpetanud keskkooli, ning samuti neil, kes olid pärit eesti-vene segaperekonnast. 12 noort (Tallinnast 6 tütarlast ja 2 noormeest ning Ida-Virumaalt 4 neiut) said riigikeele eksamil 82-93 palli. Lõputunnistusel oli neil hinne 5 ning need noored hindasid oma eesti keele oskust väga heaks. Eesti keele riigieksamil 71-81 palli saanud noori oli 16 (Tallinnast 4 tütarlast ja 4 noormeest, Ida-Virumaal olid need arvud vastavalt 6 ja 2). Neil oli eesti keele hinne kooli lõputunnistusel 4 ja nad ise hindasid oma eesti keele oskust heaks või üsna heaks. Eesti keele riigieksamil 61-70 palli saanuid oli 12 (Tallinnast 4 noormeest, Ida-Virumaalt 8 noormeest). Nende eesti keele hinne oli lõputunnistusel 3 ja ka nad ise hindasid oma eesti keele oskust rahuldavaks. 1 vastanuist hindas algul oma keeleoskust veel kriitilisemalt, kuid seda ainult kirjaliku keelekasutuse osas, lisades juurde, et pärast keskkooli on tema eesti keele kirjalik oskus siiski paranenud - seega võib ka seda keeleoskuse taset rahuldavaks pidada.

Mitte-eestlastest noorte vastuste analüüsimisel selgus, et nad ise hindasid oma keeleoskust üldiselt vastavalt sellele, millised olid nende tulemused riigikeele eksamil ning milline oli hinne lõputunnistusel. Mitterahuldavaks ei hinnanud oma eesti keele oskust keegi ning kui arvestada riigieksami tulemusi ja hindeid, samuti vestluse käigus suulist ja testi vastamisel kirjalikku keelekasutust, siis tundus, et noortel polekski olnud põhjust oma eesti keele oskuse taset ebapiisavaks pidada.

Tabelis 1 on esitatud Tallinna ja Ida-Virumaa õpilaste riigikeele eksami tulemused. Analüüsides küsitluse ja vestluse tulemusi, tundus, et tütarlastel oli keeleoskus parem kui noormeestel, samuti oli see parem Tallinna noortel. Keeleoskus oli parem ka neil, kes õppisid kõrgkoolis või olid lõpetanud keskkooli. Eesti keele oskus oli küsitluse tulemuste järgi halvem neil, kes olid lõpetanud kutsekooli. Võimalik, et seal oli õpetamise tase madalam. 
Tabel 1. Tallinna ja Ida-Virumaa õpilaste riigikeele eksami tulemuste võrdlus

\begin{tabular}{|l|l|c|c|c|c|c|}
\hline $\begin{array}{l}\text { Riigikeele } \\
\text { eksami } \\
\text { tulemus }\end{array}$ & $\begin{array}{l}\text { Hinne } \\
\text { Iópu- } \\
\text { tunnistusel }\end{array}$ & \multirow{2}{*}{$\%$} & \multicolumn{2}{|c|}{ Tallinn } & \multicolumn{2}{c|}{ Ida-Virumaa } \\
\cline { 4 - 7 } & & Neiud & Noormehed & Neiud & Noormehed \\
\hline $82-93$ & 5 & 30 & 6 & 2 & 4 & - \\
\hline $71-81$ & 4 & 40 & 4 & 4 & 6 & 2 \\
\hline $61-70$ & 3 & 50 & - & 4 & - & 8 \\
\hline
\end{tabular}

Pärast kooli lõpetamist oli 65\%-l küsitletutest eesti keele oskuse tase paranenud. Enamuses olid need Tallinnas elavad noored (10 tütarlast ja 8 noormeest). IdaVirumaalt leidsid ainult 2 vastanut, et nende keeleoskus on paranenud. Seda võib seletada sellega, et paljud Tallinna mitte-eestlased õpivad eestikeelses ülikoolis ning töötavad paralleelselt teenindajate või spetsialistidena, kus tuleb enamasti suhelda eesti keeles. See näitab, kui suur tähtsus on keelekeskkonnal - kui tuleb palju suhelda eesti keeles, siis keeleoskus paraneb.

\section{Noorte mitte-eestlaste tööhõive}

Majandusprotsesside subjektina peaksid eri rahvusest isikutel olema võrdsed võimalused tööturul (Pavelson 1997: 183). Integratsiooni tõkestav tegur on olnud muulaste jaoks riigikeele mitteküllaldane valdamine, mis takistab ka tööhõivet. Pärast taasiseseisvumist Eestis tööhõivestruktuur muutus - kahanes tootmise ja põllumajandusega seotud töökohtade arv kaubanduse, teeninduse, rahanduse ja panganduse arvel. Kõige suurem langus on olnud põllumajanduses, kus 1989. aastal oli hõivatud 177300 inimest, 2001. aastal aga 39900 (Eamets 2001). Tekkis töötus, 2001. aastaks oli juba keskmiselt 83 ooo töötut (töötuse määr 12,7\%) (samas: 16-17). Eriti raske on töökohta leida venekeelsetel noortel.

Vene kooli peamine probleem on, et kool ei suuda tagada noortele edasiõppimiseks ja edukaks tööturule liitumiseks vajalikku eesti keele oskust ning vene koolide jaoks ei jätku kvalifitseeritud eesti keele õpetajaid (Pedastsaar 1997: 281). Teine põhjus võib olla, et vene õppekeelega koolides on tööstusega seotud erialade osakaal märgatavalt suurem ja teeninduserialade määr väiksem kui eesti õppekeelega koolides. Kuna töötuse tase on keskmisest suurem just töölistel, siis kaasnevad vene õppekeelega noortel täiendavad raskused tööturul (Luuk 2001: 6-7). Seetõttu mõistetakse integratsiooni all töökeskkonnas eelkõige noorte mitte-eestlaste keelelis-kommunikatiivse integratsioonina seda, kui kesksel kohal on riigikeele omandamine (Rannut 1999: 64).

Küsitlusele vastanud noored olid kõik endale töökoha leidnud ja osa neist õppis ka kõrgemas koolis (tööhõivet on kirjeldatud tabelis 2). 60\% noortest mitteeestlastest töötas teenindajana, 35\% keskastme ja 5\% kõrgema astme spetsialistina. Tütarlapsed töötasid sagedamini teenindajana, noormehed keskastme spetsialistina. See on ilmselt tingitud sellest, et kutsekoolides on tütarlaste jaoks peamiselt teeninduserialad. Selgus, et kõrgkoolis õppivad noored töötasid peamiselt juba keskastme spetsialistina.

Teenindajana töötavatel noortel oli keeleoskus parem. 95\% küsitlusele vastanud noortest said oma tööülesannetega hästi hakkama ja keeleoskus ei olnud 
mõjutanud nende töötulemusi ega suhteid kolleegidega. 5\% (2 noormeest Tallinnast) vastasid aga, et keeleoskus on siiski nende töötulemusi mõjutanud, kuna nad ei saanud tööjuhendist aru ja sooritasid töö valesti, mille tõttu alandati neil töötasu. Tööle asudes oli noortel keelebarjäär suurem, küsitlusele vastamise ajaks olid nad aga tööga seotud spetsiifilise sõnavara juba selgeks saanud ning seetõttu ei mõjutanud keeleoskus enam oluliselt töötulemusi.

$55 \%$ noortest arvas, et nende riigikeele oskus pole takistuseks olnud nende töölevõtmisel, 30\% ei olnud sellele kunagi mõelnud ja 15\% vastanutest arvas, et neid ei võetud tööle eesti keele vähese oskuse tõttu. Diskrimineerimise kohta esitatud küsimusele vastas $80 \%$ noortest, et neid ei ole diskrimineeritud ei keeleoskuse ega ka rahvuse tõttu. 20\% (6 noormeest Tallinnast ja 2 Ida-Virumaalt) olid kogenud vaenulikku suhtumist avalikes kohtades (klubis). Tallinna noormeeste puhul piirdusid konfliktid vaidlusega, Ida-Virumaal aga tekkis kahel korral ka füüsiline kokkupõrge. Konflikti põhjustas see, et noored rääkisid vene keeles. Töökollektiivis diskrimineerimist vähese keeleoskuse tõttu ei mainitud.

Tabel 2. Noorte mitte-eestlaste tööhõive

\begin{tabular}{|l|c|c|c|c|c|}
\hline \multirow{2}{*}{} & \multirow{2}{*}{$\%$} & \multicolumn{2}{|c|}{ Tallinn } & \multicolumn{2}{c|}{ Ida-Virumaa } \\
\cline { 3 - 6 } & & Neiud & Noormehed & Neiud & Noormehed \\
\hline Teenindaja & 60 & 8 & 4 & 6 & 2 \\
\hline Keskastme spetsialist & 35 & 2 & 4 & 4 & 8 \\
\hline Kõrgema astme spetsialist & 5 & - & 2 & - & - \\
\hline
\end{tabular}

\section{Mitte-eestlastest noorte suhtlemine eestlastega}

Küsitluse analüüsimisel selgus, et suurem osa vastanutest suhtles eestlastega vähemalt paar korda nädalas. Parema keeleoskusega noored suhtlesid eestlastega sagedamini ning nad leidsid, et kui nad kasutavad rohkem eesti keelt, siis paraneb ka nende keeleoskus. Suhtlemist eestlastega väljaspool tööd on kirjeldatud tabelis 3 .

Iga päev suhtles eestlastega 50\%, s.o 20 noort (Tallinnast 6 tütarlast, 4 noormeest, Ida-Virumaalt 6 neidu ja 4 noormeest). Nendest vastanutest 12 olid pärit segaperekonnast, kus üks lapsevanem oli eestlane - seega on neil ka eestlastest sugulasi ja sõpru. Paar korda nädalas suhtles eestlastega 12 noort (Tallinnast 2 tütarlast, 4 noormeest, Ida-Virumaalt 4 neiut, 2 noormeest). Need noored käisid spordisaalis ja ujulas, kus sportisid ka eestlased, treeningutel. Samuti oli neid tuttavaid, kellega iga päev kokku ei saadud. 4 noort (Tallinnast 2 tütarlast ja 2 noormeest) kohtusid väljaspool tööd eestlastega umbes üks kord nädalas juhuslikult. 4 noormeest Ida-Virumaalt ei suhelnud väljaspool tööaega praktiliselt kunagi eestlastega. Neil polnud ka eestlastest sõpru ega naabreid. 
Tabel 3. Mitte-eestlastest noorte eestlastega suhtlemise sagedus väljaspool tööd

\begin{tabular}{|l|c|c|c|c|c|}
\hline & \multirow{2}{*}{$\%$} & \multicolumn{2}{|c|}{ Tallinn } & \multicolumn{2}{c|}{ Ida-Virumaa } \\
\cline { 3 - 7 } & & Neiud & Noormehed & Neiud & Noormehed \\
\hline Iga päev & 50 & 6 & 4 & 6 & 4 \\
\hline Paar korda nädalas & 30 & 2 & 4 & 4 & 2 \\
\hline Üks kord nädalas & 10 & 2 & 2 & - & - \\
\hline Mitte kunagi & 10 & - & - & - & 4 \\
\hline
\end{tabular}

\section{Meedia roll integratsiooniprotsessis}

Teave Eesti kohta peab olema kättesaadav kõigile ühiskonnaliikmetele, kuid Eesti ühiskonnas on tuntav rahvuslik-keeleline eristumine meedia valdkonnas (Saks jt 2000).

Eestis on olemas eesti- ja venekeelsed ajalehed, raadio- ja televisioonikanalid, millel on vähe ühist. Meedia suure tähtsuse tõttu tänapäeva ühiskonnas on oluline julgustada eri kogukondade omavahelist suhtlemist, toetada nende meediakanalite arengut, mis oleksid ühised nii eesti- kui ka muukeelsele elanikkonnale. Kõigi ühiskonnaliikmete osalemine riigi avalikus elus näitab, et tegu on integreeritud ühiskonnaga. Meedia peab töötama ühises suunas muude valdkondadega. Eestikeelsete programmide puhul tuleb arvestada ka teiskeelse vaatajaga (Saks jt 2000).

Küsitluse põhjal selgus, et 10\% vastanutest vaatas ainult eestikeelseid telesaateid. Nendel noortel (4 tütarlast Ida-Virumaalt) puudus kodus kaabeltelevisioon ja seega oli võimalus vaadata ainult eestikeelseid telekanaleid. 15\% vaatas ainult Venemaa telekanaleid (kõik olid idavirumaalased). Kõige rohkem vaadati dokumentaalfilme, teleseriaale, viktoriini- ja spordisaateid. Nii Eesti kui ka Vene telekanaleid vaatasid 40\% vastanutest ehk 16 noort. Eesti saadetest nimetati uudistesaateid, noorte- ja spordisaateid, lisaks teleseriaale. 35\% vaatajatest jälgis nii Eesti, Venemaa kui ka kaabeltelevisiooni kanaleid.

Tehtud uurimusest nähtus, et kõige suurem osa (40\%) noori jälgib nii Eesti kui ka Vene telekanaleid. Ainult viimaste kasutajaid ei ole palju. Üldiselt vaatasid parema eesti keele oskusega noored kõiki kanaleid.

\section{Mitte-eestlastest noorte tulevikuplaanid}

Eestiga seostas oma tulevikuplaane 65\% uuringus osalenud noortest. Nad põhjendasid seda sellega, et Eesti on nende kodumaa, siin elavad nende vanemad, sõbrad, sugulased ning nad lootsid, et saavad siin hea hariduse ja tasuva töökoha ning edaspidi karjääri teha.

Oma saatuse otsustas Venemaaga siduda 10\% noortest (4 noormeest IdaVirumaalt). Kahel neist elas üks vanematest Venemaal ning kõigil elas Venemaal suurem osa sugulastest. Nad arvasid, et tutvuste abil saavutavad nad Venemaal rohkem kui Eestis. 
Muude riikidena, millega sooviti oma tulevik siduda (25\% vastanutest), nimetati ka Saksamaad. Küsitletud noormehed olid olnud Saksamaal vahetusõpilastena ja neile pakuti seal edasiõppimisvõimalusi. Neiud aga otsustasid tööle asuda kas või ainult aastaks lapsehoidjate ja koduabilistena, hiljem lootsid nad Saksamaal siiski edasi õppida.

Iirimaaga soovis oma tulevikku siduda 4 Tallinna noormeest. Nad olid ajalehest tööpakkumisi lugenud ja otsustasid just sellel maal õnne proovida. 2 noormeest Tallinnast otsustasid Islandi kasuks, kuna seal elasid neil sugulased. Nemad ei olnud küll kindlad, kas nad sinna maale elama jäävadki.

Kõikide küsitletute hulgas oli arvuliselt rohkem neid, kes soovisid elada Ees-

tis, kuid ka neid ei olnud vähe, kes tahtsid siit lahkuda. Põhjenduseks toodi, et Eesti on siiski väike riik ja siin on eduvõimalused väiksemad, kuna konkurents tööturul on suur. Kõigil neil, kes soovisid Eestist lahkuda, olid välismaal kas sugulased või oli läbi mõeldud enam-vähem kindel tegevuskava. Oma tulevikuplaanide tegemisel oli arvesse võetud nii eesti kui ka inglise keele oskust, samuti leidus noori, kes ei olnud oma töökohaga rahul.

Tuleviku suhtes tundis ennast kindlalt 60\% vastanutest. Kindlalt ei tundnud 25\% (Tallinnast 1 neiu, 3 noormeest, Ida-Virumaalt 6 noormeest) ning 15\% ei olnud sellele mõelnud. Tuleviku suhtes tundsid ebakindlust need mitte-eestlased, kelle eesti keele oskus ei olnud eriti hea. Samuti olid nad kogenud ebasõbralikkust ametiasutustes ning valdavalt polnud nad oma tööga rahul.

\section{Kokkuvõte}

40-liikmelise noorterühma seas läbiviidud küsitlusest selgus, et oma eesti keele oskust hindas enamik heaks (40\%), rahuldavaks ja väga heaks aga 30\%. Antud grupi puhul oli tütarlastel keeleoskus parem kui noormeestel, parem riigikeele oskus oli eesti-vene segaperedest pärit noortel, samuti Tallinna noortel.

Kõik küsitlusele vastanud töötasid kas teenindaja või keskastme spetsialistina, kõrgemas koolis õppijad harilikult keskastme spetsialistina, 2 noormeest olid aga isegi kõrgema astme spetsialistid.

Pooled küsitletutest suhtlesid eestlastega väljaspool tööd iga päev. Neil oli üks vanematest eestlane, neil oli eestlastest sugulasi ja sõpru. Eestlastega ei suhelnud väljaspool tööaega ainult 4 noort Ida-Virumaalt, kuna neil lihtsalt polnudki sõpru ega häid tuttavaid eestlaste hulgas.

Meediast jälgitakse valdavalt Vene ja Eesti meedia kombinatsiooni (40\%), samuti pole väike osa Lääne meedial. Eesti telekanalitelt vaadatakse peamiselt noortesaateid, seriaale, filme, spordisaateid ja uudiseid, Vene telekanalitelt aga põhiliselt mälumänge ning samuti teleseriaale, filme ja spordisaateid.

65\% küsitletud noortest seostavad oma tulevikuplaane Eestiga. Nad loodavad siin saada hea hariduse, tasuva töö ning edaspidi samuti karjääri teha. 35\% leiab, et Eesti on väike riik ja siin on võimalused edu saavutada väiksemad, tööturg on samuti suhteliselt väike. Suurel osal nendest elavad sugulased ja tuttavad välismaal ning nad loodavad neilt abi saada.

Kuigi pärast taasiseseisvumist on ettevõtetes tulnud juurde keelenõue, pole see töösuhteid rikkunud. Rahvustevaheliste probleemide puudumine tuleneb 
pikast koostööharjumusest, ametialasest või elukutse identiteedist ja töötajate suhteliselt kõrgest haridustasemest, millega kaasneb ka parem keeleoskus. Erinevast kultuursest ja rahvuslikust taustast tulenevaid takistusi ja diskrimineerimist koostöötamisel ei tunnetata. Mitte-eestlastest noorte arvates seda nende ettevõttes ei toimu ning töötajaid hinnatakse töölevõtul, koondamise korral ja töötasu osas kvalifikatsioonist ja töössesuhtumisest lähtuvalt. Siiski on esinenud konflikte ametiasutustes ja olmetingimustes suhtlemisel, kus on üheks põhjuseks ka vähene eesti keele oskus. Samuti on puuduliku keeleoskuse tõttu olnud mõningaid arusaamatusi tööl.

Analüüsides küsitluse vastuseid seostatuna keeleoskuse, hariduse ja rahvusega, võib järeldada, et need noored, kelle keeleoskus on parem ja hariduse tase kõrgem, on edukamad oma töös, nende tulevikuplaanid on põhiliselt seotud Eestiga, nad tunnetavad vähem isoleeritust, tõrjutust, diskrimineerimist rahvuse tõttu ning tunnevad ennast tuleviku suhtes kindlamana.

Kutsehariduse omandanud noored, osaliselt ka keskharidusega noored, kelle keeleoskus pole nii heal tasemel, pole oma tuleviku suhtes nii kindlad, samuti seostavad nad oma tulevikku rohkem teiste riikidega ja tunnetavad tugevamini diskrimineerimist. Seda rühma võib nimetada mitte-edukaks rühmaks.

\section{Kirjandus}

Eamets, Raul 2001. Eesti ja Euroopa tööturg muutuvas maailmas. - Postimees, 16. mai, $16-17$.

Hallik, Klara; Meri, Mart; Taagepera, Rein; Tammaru, Jüri; Venesaar, Urve 1997. Muulaste integratsioon Eesti ühiskonda. ÜRO Arenguprogramm. Avatud Hariduse Liit. Tallinn.

Kallas 2001 = Каллас, Роман 2001. Об адаптации российских переселенцев в Эстонии (конец XIX до I половина XX века). - Радуга, № 4, 86-104.

Kallas 2002 = Каллас, Роман 2002. Педагогика на перекрестье культур. - Радуга, № 4, 112-120.

Küün, Elvira 2004. Mitte-eestlastest noorte kohanemine eestikeelses töökeskkonnas. Bakalaureusetöö. TLÜ eesti keele õppetool. Tallinn.

Liebkind, Karmela 1995. Dispersial Xenohobia and Acculturative Stress. Refugees in Finland. - Multiculturalism in the Nordic societies: proceedings of the $9^{\text {th }}$ Nordic seminar for researchers on migration and ethnic relations: final report. Ed. by Jan Hjarnø. Copenhagen: ThemaNord, 261-273.

Luuk, Mai 2001. Eesti ühiskonna integratsiooniprotsessi sotsiaalne ja majanduslik aspekt: ümarlaud. Ettekanne Inimõiguste Teabekeskuse konverentsil 23.11.2000. Inimõiguste Teabekeskus. Tallinn.

Pajupuu, Hille 2000. Kuidas kohaneda võõras kultuuris? Tallinn: TEA.

Pavelson, Marje 1997. Mitte-eestlased Eesti tööturul. - Vene noored Eestis: sotsioloogiline mosaiik. Projekt "Vera". Koostaja Priit Järve, toimetaja Mati Heidmets. Tallinn: Avita, 183-195.

Pedastsaar, Tiia 1997. Venekeelsete õpilaste Eesti ühiskonda integreerumise ühe võimaluse analüüs. - Vene noored Eestis: sotsioloogiline mosaiik. Projekt "Vera”. Koostaja Priit Järve, toimetaja Mati Heidmets. Tallinn: Avita, 281-287.

Rahvaloendus 2000 = Eesti Statistikaameti rahvaloendus 2000. http://www.stat.ee// gatekeeper.stat.ee:800o/px-web.2001/Database/Rahvaloendus_regionaalne/ Rahvaloendus_regionaalne.asp (30.04.2004). 
Rannut, Mart 1999. Keeleõpetus kui keeleõppepoliitika osa. - Keelekümblus kui integratsiooni võti. Koostanud Silvi Vare. Tallinn: Aura, 61-66.

Rannut, Mart; Rannut, Ülle; Verschik, Anna 2003. Keel, võim, ühiskond. Tallinn: TPÜ Kirjastus.

Saks, Katrin; Lukas, Tõnis; Lauristin, Marju; Meri, Mart; Ojuland, Kristiina; Pavelson, Marje; Taagepera, Rein; Rannut, Mart; Heidmets, Mati 2000. Integratsioon Eesti ühiskonnas 2000-2007. Riiklik programm. Kiidetud heaks Vabariigi Valitsuse poolt 14.03.2000. Tallinn: Merkest.

Skutnabb-Kangas, Tove 2000. Linguistic Genocide in Education - or Worldwide Diversity and Human Rights. Mahwah, New Jersey, London: Lawrence Erlbaum Associates.

Trasberg, Karmen 2002. Maailma mitmekesisus ja kultuuride kohtumine. - Haridus mitmekultuurilises perspektiivis. Toim Karmen Trasberg. Tartu: Tartu Ülikooli Kirjastus, 11-17. 


\section{THE ADJUSTMENT OF THE NON-ESTONIAN YOUTHS INTO THE ESTONIAN SPEAKING WORK ENVIRONMENT}

\section{Elvira Küün}

Integration is a national policy of Estonia. We aim to create the Estonian model of a balanced multicultural society in which the ethnic differences do not restrain any individual's personal enhancement. Such a society is characterised by everyone's opportunity of fulfilment of his/her personal potential, by the strong common core of the society and by the central role of the Estonian culture.

Currently there are over 100 non-Estonian nationalities and ethnic groups in Estonia. The major obstacle that prevents most of these people from participating in the Estonian life and from having better opportunities in the labor market is the insufficient knowledge of the Estonian language.

The language barrier has created a situation that the non-Estonians feel being trapped into their own world. The opinion surveys conducted in the recent years have revealed a potential threat: the development of two different societies in Estonia, both having their own language and mentality. We shouldn't lose time in removing the barriers between the Estonian and non-Estonian communities.

There are two parallel processes in harmonizing the multiethnic society. The first process in the social harmonization of the society is the minorities acquiring a basic knowledge of Estonian and the Estonian citizenship. The second process is the preservation of the ethnic differences though recognition of the cultural right of the ethnic minorities.

The components of the Estonian integration policy are: orientation to the future; focus on the children and the youth; integration as a development opportunity for the Estonians and the non-Estonians; active participation of the nonEstonians in the integration process; elimination of the indifferent and passive attitude; the feeling of security and tolerance throughout the society; changing the attitudes (to see the non-Estonians are a potential of the country's development, not an obstacle); development the Estonian education system to be the main actor in integration policy; noticeable increase within the coming years in the command of Estonian among the non-Estonians; adaptation of non-Estonians into the Estonian cultural space; reduction of their regional isolation; determination of their citizenship; political integration of the ethnically nonEstonian citizens into the legislative and executive power structures.

It is difficult to find the one and only good solution on how to adapt the nonEstonians into the Estonian society, nevertheless, compromises and better solutions for the coexistence of big national groups must be pursued.

Keywords: integration, language policy, bilingualism, second language acquisition, Estonian as a second language 
Elvira Küün (1980) on lõpetanud Tallinna Pedagoogikaülikooli eesti keele (kui võõrkeele) erialal 2004. a. Töötab Tallinna Mustjõe Gümnaasiumis õpetajana ja Päevalehes keeletoimetajana, õpib Tallinna Ülikooli magistrantuuris. Tegeleb tõlkimise ja toimetamisega. On varem uurinud vene emakeelega õpilaste kohanemist eestikeelses üldhariduskoolis, riiklikku ning Tallinna integratsiooniprogrammi. Samuti on käsitlenud tsitaatsõnade esinemust ajalehekeeles. elvira22@tlu.ee 